Dobell, A.R.

"Some Characteristic Features of Optimal Control Problems in Economic Theory." IEEE Transactions on Automatic Control AC-14.1 (1969): 39-48.

Reprinted with permission from

The Institute of Electrical and Electronics Engineers 


\section{Expository Papers}

\section{Some Characteristic Features of Optimal Control Problems in Economic Theory}

\section{A. R. DOBELL}

Abstract-This paper formulates the system equations, state and control space constraints, and a criterion functional for an elementary example of a problem in economic growth, and discusses some further interpretation of the underlying economic structure. Several examples are presented to illustrate particular features of control problems in economics; references to futher examples, and to more general work in mathematical economics, are cited.

\section{INTRODUCTION}

New developments in the theory of economic growth raise a number of issues of interest to control theorists. This paper suggests a framework which may be helpful in studying economic growth models and gives reference to mathematical discussions of the principles underlying some of the economic problems to which control theory can usefully be applied.

The material divides roughly into four sections:

1) formulation of a simplified but typical control problem in economic theory;

2) economic interpretation of some features of the control problem:

3) some examples of further applications; and

4) some comment on features which might be peculiar to economic examples and which warrant further study.

This paper begins, then, with a brief consideration of how economic theory leads naturally to the formulation of some problems which appear familiar to people interested in optimal control.

\section{Typical Example}

\section{A. State of an Economic System}

The description one might take of the state of an economic system is a record, at the specified instant, of its inventory of machines and equipment of all kinds, its stock of buildings and structures, its population and labor force and their composition, its inventories of natural resources, and its stockpiles of finished goods, along with a record of flows and transactions between various agents or groups within the economy, Features of a standard "position and velocity" description are evident, even though the dimensionality may seem formidable.

However, one feature in economic models is not standard and permits drastic reduction in the number of state variables to be considered. For most economic examples, it is assumed that a "static allocation problem" can be solved to the point where the flow rates of change at any moment are either determined by the position variables (the stock levels) at that moment, or are themselves control variables or functions of control variables, subject to choice at that moment. ${ }^{1}$ The result is that one can take the position variables or stock levels at any moment as a complete specification of the state.

In discussing stocks of assets, a distinction is made frequently between capital goods, such as machines and buildings, which are produced within the system at rates subject to control, and primary factors, such as land and labor, the growth rates of which are not under

Manuseript received July 11, 1968. An earlier version of this paper was prepared as background for discussion in a Control Theory Seminar at the Electronics Research Center National Aeronautics and Space Administration, Cambridge, Mass., January 24, 1968.

The, Aussor is with the University of Toronto, Toronto, Ont., Canada.

Discusion of this static allocation problem is given in more detail in Section III. The implicit assumption that the distribution of asset stocks among individuals or classes of individuals can be ignored, should be noted. Although this assumption is common in aggregate economies, it is obviously quite extreme. the control of the hypothetical economic planner. Obviously, to the extent that one can reclaim land and train labor to higher productivity, this distinction is somewhat fuzzy, but the presence of primary factors may have the effect of introducing some nondiscretionary element into the evolution of the system. At any rate, most recent growth models have tended to deal with one primary factor, labor, whose growth is not influenced by any control variables, and a small number of distinct capital goods which are produced within the system. The state is thus specified by a finite-dimensional vector whose components represent the levels of these various capital stucks and labor. ${ }^{2}$ (Inventories of raw materials and stockpiles of finished goods are ignored in these analyses. ) In particular, for the sake of example, it may be assumed that it is not necessary to distinguish different kinds of machines, so that one may describe the level of the capital stock (measured as a number of machines of specified capacity) by the symbol $K(t)$, and the number of (indistinguishable) laborers by the symbol $L(t)$. In this simplest example the state is represented, then, by the vector $(K(t), L(t)) .^{3}$

\section{B. System Equations or Transition Equations}

Taking the vector $(K, L)$ to specify the state at any time, it is required that economic theory explain the deternination of $K$ and $L$. The underlying economic characteristic to be reflected in the example is, first, that the rate of increase of the labor force is to a large extent determined by two factors which are themselves the product of noneconomic considerations. These two factors are the rate of population growth and the proportion of the population which participates in production as members of the labor force. The rate of population increase presumably depends on sociological consideration, psychological issues, and moral pressures, all usually considered outside the realm of economic theory. The labor force participation rate, while clearly responding to economic considerations, is frequently assumed to be near enough constant as to justify, as a rough approximation, taking the labor force to be a constant fraction of the population. (Of course, these assumptions can be weakened.) The upshot of such argument is that one system equation in the example takes the form

$$
\dot{L}(t)(\text { men } / \text { year })=n(t)(\text { per year }) \cdot L(t)(\text { men })
$$

where it is usually assumed that $n(t)$ is a given positive constant.

On the other hand, while the labor force may be a matter which is determined by considerations outside the influence of economists or social planners, it is clear that the rate of increase of the capital stock -which is what the economist calls "net investment."-is decidedly a product of economic decisions.

On the one hand, there is the whole set of considerations stemming from the fact that directing resources to the production of new machines and equipment to be added to the capital stock means diverting resources from the production of goods which could be used for current consumption and enjoyment. Since the purpose of accumulating capital goods now must be to create capacity to produce consumer goods in the future, the decision becomes one of trading off consumption now for the sake of consumption later. This saving decision determines the resources which could be made available for producing additions to the capital stock.

But new machines and equipment have to be ordered, or at least orders for them have to be anticipated, before anyone is willing to

2 A problem arises with one class of growth models (the so-called "vintage" models) in which capital goods produced at different times bave different char acteristics. In general, it will no longer be possible to adopt such a finite state space description for these models, and so far there are few results other than steady-state results available. See $[54,9 \mathrm{a}]$.

Since it is assumed that labor force growth is not influenced by any contro variable, the second component of this vector is a simple funetion of time alone. Later the reduction of this system to a single state variable will be made explicit. 
produce them. Thus against the resource availability side, the saving side, one has to place the demand for new equipment, the investment side. From the two independently determined quantities-the resources demanded by producers desiring to invest in new capacity and the resources potentially available from savers prepared to defer current consumption to acquire a claim against future consumption-a realized flow rate of additions to capacity is determined (assuming depreciation and required replacement are made good separately).

One simplified set of hypotheses supposes that the community in the aggregate makes available, for purposes of investment in new capacity, resources equal to some specified fraction of national income. At the same time it is supposed that, by suitable national policy, demand for investment goods is brought into line with available saving, so saving decisions are always realized. These assumptions may be expressed, ignoring depreciation, by the equations:

$$
\dot{K} \text { (machines/year) }=I(\$ / \text { year }) \cdot 1 \text { machine } / \mathrm{s}
$$

which expresses the way in which investment expenditures $I$ are translated into increases in productive capacity measured in physical units;

$$
S(\$ / \text { year })=s Y(\$ / \text { year })
$$

which expresses the saving decision of the community; and

$$
I(\$ / \text { year })=S(\$ / \text { year })
$$

which expresses the equilibrium condition that the desired rate of investment expenditure be reconciled, presumably by some monetary or fiscal policy of the central government, with the saving behavior of the community. ${ }^{4}$ These equations thus lead to the simple system equation

$$
\dot{K}=s Y
$$

where $s$ is a positive (dimensionless) constant and $Y$ is national income measured in $\$ /$ year. $^{5}$

To express national income in terms of the state variables is the final task in developing system equations for the simplified model. For this, one goes to a body of the economic literature dealing with "production functions." Solow [91] surveys this literature, which attempts to derive empirically the form of statistical relationships (corresponding in principle to engineering functions) linking output to inputs of machine services and labor services. From such study is derived a relationship

$$
Y=F(K, L)
$$

where the function $F$ is usually assumed to be a positive function having at least two continuous derivatives with

$$
\begin{aligned}
& F_{K}(K, L)>0, \quad F_{L}(K, L)>0 \\
& F_{K K}(K, L)<0, \quad F_{L L}(K, L)<0
\end{aligned}
$$

and to be positively homogeneous of degree one in $K$ and $L$. (To be precise, the variables $K$ and $L$ entering the function $F$ should be interpreted as multiplied by a utilization factor of unity, having dimensions machine-years/year/machine and man-years/year/man, respectively.)

Assuming the existence of such a production function, one may then write the basic system equations purporting to describe the aggregate economy (i.e., the "plant" the economist studies) in this example as

$$
\begin{array}{ll}
\dot{K}=s F(K, L), & K(0)=K_{0} \\
\dot{L}=n L, & L(0)=L_{0} .
\end{array}
$$

4 Equation (4) may be interpreted as a condition that must be satisfied if the economy is to be operating at full employment, that is, it is an equation which assumes that the problems of short-run economic stabilization bave been adequately solved. For purposes of studying the long-run evolution of an economy, this may be a justifiable assumption.

5 Here the unit $\$$ is to be interpreted simply as a unit of homogeneous physical product. There is no provision in this simple example for changing prices.

\section{Constraints on Controls and State Space}

If the aggregate saving rate $s$ is completely determined and social policy is directed in such a way as to ensure realization of that saving rate through investment decisions, then the evolution of the whole system is itself completely determined once initial conditions are specified. (Study of the behavior of this system with specified saving rate, which is often referred to as the Solow model [92], has been extensive, as has been discussion of similar models with slightly different theories determining individual saving. ${ }^{6}$ See [33].) Suppose, on the other hand, that the saving rate of individuals can be influenced by various incentives or short-run social policies, so that the aggregate saving rate becomes an instrument of long-run social policy or a control variable. Then the problem becomes a conventional problem in control theory with one obvious constraint, namely, that the saving rate $s$ is only to take on values which could in fact be realized by some feasible social policy. Since $s$ is a proportion of output saved and directed toward capital accumulation, it is, in a closed system, clearly limited to values in the unit interval and may, in fact, be still further restricted for economic reasons.

Moreover, economic quantities generally share the feature belonging to concepts like miss distance or aircraft height above ground: they cannot assume negative values. Hence we must impose the conditions

$$
K \geq 0, \quad L \geq 0
$$

along with the control space constraint $0 \leq s \leq 1$. Thus we have a state-space description, system equations, and control and statespace constraints. What is required now is a method to evaluate the desirability of various trajectories satisyfying all the imposed conditions.

\section{Criterion}

In discussions of economic growth it is usually assumed that ultimate concern attaches to the welfare of households, not firms or other intermediate agents created only as part of a system to serve households. This suggests that the performance of an economy should be measured by the final consumption levels it makes possible. (Of course, this criterion must be tempered by consideration of the distribution of consumption and of wealth, but it is of ten assumed in problems of the type considered here that these matters can be taken care of by some political process-that a higher rate of consumption flow can be appropriately redistributed so as to leave everybody better off.)

But since an economy produces many different goods for consumption purposes, one must consider how to evaluate various output combinations. Therefore, consider for a moment a (column) vector $C$, whose components indicate the rates of consumption desired by one individual of each of the many goods available. To explain the determination of this vector, that is, to explain an individual's demand for goods and services, early theorists proposed that each individual possessed a utility function $U(C)$ defined on this consumption space or space of consumption bundles. These theorists then viewed the consumer's decision as one of maximizing this indicator $U$ subject to restrictions on total expenditure and to non-negativity restrictions. Specifically, the problem was: for given $p, E$, where $p$ is a given row vector of positive prices and $E$ is a given positive constant, maximize $U(C)$ subject to $p C \leq E, C \geq 0$. The resulting value $U(C)$ was to be taken as an indicator of consumer satisfaction.

This was the classical problem of consumer's choice, a static problem in possibly many dimensions. With sufficient regularity assumed for the function $U$, some meaningful propositions may be obtained about changes in the solution vector $C$ in response to changes in the

6 It is also possible that saving decisions of individuals may be made in accord with individual integral criterion functionals, thus leading to a descriptive mode in which explicit individual long-run maximizing behavior is part of the uncontrolled system. But discussion of this issue must be deferred to Section III. 
parameters $p, E$. For discussion of such "laws of demand," one can see Houthakker [40], and Samuelson [74].

More recent work has been directed toward replacing the utility function $U$ with a general preference ordering defined on the vector space of consumption bundles $C$ and to investigating the axiomatic basis for such ranking procedures. The interesting questions of determining the mathematical properties of the choice functions $C(p, E)$, which would imply the existence of an underlying preference order having the desired regularity, and the conditions under which this ranking in turn may be represented by a numerical-valued function, have largely been resolved. See Debreu [19], Houthakker [41], Richter [71], Samuelson [75], and Uzawa [102] for examples of this discussion.

Despite its mathematical elegance, this literature has two defects for present purposes. One is that it applies to individuals and appropriate workable procedures for aggregation are not obvious. The second, and for the moment more important, is that it is too static; it says nothing about decisions to forego consumption and accumulate purchasing power for later use. One can, however, think of a dynamic counterpart to the preceding problem. Let $C(t)$ be a vectorvalued function of time $t$, for $0 \leq t \leq T$. (In the simplest case, one takes $C(t)$ to have one component only, representing the consumption path with a single consumption good.) One then seeks, in analogy with the previous approach, a procedure for ordering the elements (now functions) in this space of consumption paths $\{C(t): 0 \leq t$ $\leq T\}$.

The most general procedure would be to establish some axiomatic basis for a preference ordering on the space. For examples of this work, one may see Diamond [21] and the references cited there.

A slightly less ambitious scheme would be to search for any mapping, any functional, from this consumption space to the real line. This seems unworkable in general. (But see Radner [111].) Therefore, a still less general scheme is to suppose that there is an instantaneous utility function of the previous sort $U(C, t)$, which at any time $t$ provides the basis for ranking consumption bundles just as before, and then to suppose further that a suitable functional on the space $\{C(t): 0 \leq t \leq T\}$ to the real line $R$ is the additive form

$$
J=\int_{0}^{T} U(C, t) d t
$$

It should be emphasized that specialization of the functional to this form assumes a very strong independence (additivity) through time..$^{\top}$

Further specialization entails the assumption that the influence of time works uniformly on all goods, so that $U(C, t)$ may be decomposed into a timeless utility function $U(C)$ and a discount factor $\alpha(t)$. Thus the criterion becomes

$$
J=\int_{0}^{T} U(C) \alpha(t) d t
$$

and if it be assumed that the discount factor $\alpha(t)$ has exponential form, then one obtains the common criterion

$$
J=\int_{0}^{T} U(C) e^{=\rho t} d t
$$

This applies still to an individual. ${ }^{8}$ However, by a leap of faith, one could say that all components of the consumption vector are to i It can also be noted that any monotonically increasing transformation of the index $f$ will preserve the ranking assigned by the criterion, but that any transformation of ${ }^{i}$ other than a linear transformation will amount to changing the weighting scheme attached to utilities and, therefore, will not preserve the order assigned by $J$. This means that the function

8 . In the microeconomic theory of the individual consumer, the work of Yaari [107] and others builds on such "life-cycle" or "permanent income" concepts. Similar concepts are useful in theories of individual portfolio management or in problems of investment in education and so-called "human capital." It is a ohallenging exercise to bring this type of theory of individual behavior into an aggregate growth model. be interpreted in per capita terms, denoted by lower case letters, and that the utility function $U(c)$ may be interpreted as appropriate for a representative man or for the community as a whole.

Three issues involved in this leap are troublesome, however. For an individual, it may be appropriate to take $T$ to be the expected lifetime or, perhaps, to take $T$ to be a random variable with finite expected value. (Yaari [107] studies this latter approach.) But for an entire community, what is the appropriate value to be assigned to $T$ ? Secondly, individuals may in fact display impatience and systematically discount future enjoyment in comparison to present. But can this be appropriate for enlightened direction of the community as a whole? Finally, if the criterion is expressed in terms of per capita consumption, should not the integrand be weighted by the population size to ensure that all individuals receive equal attention whether they live at a time of many people or few? On these issues there is still discussion, for example, in Ramsey [70], Koopmans [48], Samuelson [77], Lerner [0ँ3], and others.

If the horizon is taken as infinite and a zero discount rate-or weighting by a population growth rate in excess of the discount rateis assumed, then the convergence of the integral $J$ cannot be taken for granted. In the borderline case of zero discounting, it is possible that the simple trick of measuring $U(c)$ from an equilibrium or "bliss" level $U$ may yield a meaningful ordering. (This trick is used by Ramsey [70] and discussed in detail by Koopmans [48].) Otherwise, the criterion $J$ does not define a sensitive ordering on all of $\{c(t): 0 \leq$ $t \leq T\}$, but rather assigns the value $+\infty$ to distinct paths among which the analyst may be able to express an unambiguous preference. To meet this problem, the so-called "overtaking" or "partial sum" criterion was suggested: one seeks a path $c^{0}(t), 0 \leq t \leq T$, such that for any other path $c(t)$, there exists $T^{0}$ such that

$$
J^{0}=\int_{0}^{\mathrm{T}} U\left(c^{0}, t\right) d t \geq \int_{0}^{\mathrm{T}} U(c, t) d t, \text { for all } T \geq T^{0} .
$$

Weizsäcker [105] and McFadden [59] discuss this criterion and the conditions under which rankings under it might agree with rankings under the earlier criterion.

Before leaving discussion of the performance index for an economy, it may be observed that $C$ at any time can be taken to be a function of the state and the control variables, so that the criterion functional really depends only on the time paths for these variables and the initial state. Thus if one wished not to commit himself on the claim that only final consumption is relevant to social welfare, he could formulate the utility indicator simply as a function of state and control variables, without altering any of the preceding comments significantly.

Thus one has a state description, system equations with given initial conditions, and a criterion functional to be maximized subject to imposed state and control constraints. Each of these components of the control problem is seen to arise naturally in the context of standard economic theory. Before passing to some specific examples, it may be appropriate to look briefly at some further interpretation of the problem.

\section{Further Economic Interpretation}

In the preceding example, the final formulation of the system to be studied was

$$
\begin{aligned}
& \dot{K}=s Y, \quad K(0)=K^{0}, \quad K(t) \geq 0 \\
& \dot{L}=n L, \quad L(0)=L^{0}, \quad L(t) \geq 0 \\
& Y=F(K, L) \\
& 0 \leq s \leq 1 .
\end{aligned}
$$

This simple example illustrates some features of a fairly general case, which might be written as 


$$
\begin{aligned}
& \dot{K}=f(K, Y, u, t) \\
& 0 \leq G(K, Y, u, t) \\
& u \in \Omega
\end{aligned}
$$

where $K, Y$, and $u$ are all to be vectors. The additional constraints in the system $G$ stem from the "static allocation problem" referred to before. To explain the significance of this issue in economic problems requires a short digression into static economic theory.

One of the characteristic features of an economic system is that it is driven by a mechanism involving many conscious individual decisions, all somewhat interdependent and simultaneously undertaken. There is, therefore, need for an explicit theory to explain how the system configuration is determined at any given instant, before even considering the evolution of the economic system over time.

To simplify the issue, the economic theorist introduces the notion of competitive markets and thereby succeeds in treating as independent a number of decisions which previously were highly interdependent. This remarkable analytical device, which permeates economic theory, will prove to be closely related to the central analytical device in systematic treatment of optimal control problems. (Precisely in the cases where the assumption of competitive markets is untenable, one has to deal with all the intractable problems of interdependent decisions which in economics go under the names of oligopolistic or duopolistic warfare, undue exercise of market power, or rivalrous competition and which in theory might have to be described by immense problems in differential games or something similar.)

The idea is straightforward. One introduces auxiliary variables (prices) which each decision maker treats as given parameters, in the light of which he makes his individual decisions. A "market" mechanism is imagined to tally all individual decisions and to adjust the auxiliary variables until all individual decisions are consistent one with another. ${ }^{9}$ It usually turns out also that under these circumstances the resulting system configuration satisfies some principle of efficiency analogous to the principle of least action, sometimes deseribed as the principle of the invisible hand. ${ }^{10}$

As an analytical technique the trick cannot be bettered. What is particularly interesting is that it was not in fact developed as an analytical trick, but actually was intended as a description of the way in which an economic system seems to operate. The auxiliary variables, in other words, may not be simply analytical constructs determined by substitution into some equality constraint, but extant observable quantities capable of being read from a catalog or a ticker tape; not only conceptually determined but visible and capable actually of guiding a system to a configuration in which innumerable individual decisions are all mutually consistent.

What makes up the "system" referred to previously" How is it to be described? In a simplified breakdown one might separate decision-making agents into only two classes, "households" and "firms," with primary importance attaching to the welfare of the former, the firms ultimately being merely instruments to serve the needs of households by organizing production activities. For the moment it will not hurt to talk also as if ownership of all capital and labor resides with households.

Furthermore, one might postulate that firms transform the services of existing machinery and equipment and of labor into output of new machinery and also of goods for households on terns established by the existing technology. Households in turn acquire goods and offer services for production. (See Fig. 1.) Thus one could deal in the simplest case with only three markets-for goods, for capital

9 This notion of "groping" toward static equilibrium prices which clear al markets will be elaborated later.

10. At least four technical issues have to be considered in formal analysis of such price systems, namelyz, the existence of an equilibrium configuration. its uniqueness if it exists, its welfare significance, and the convergence or stability of adjustment processes seeking the equilibrium configuration. On these questions one may refer, for example, to Debreu [19], Arro
Hurwiez [3], and Arrow, Block, and Hurwicz [5].

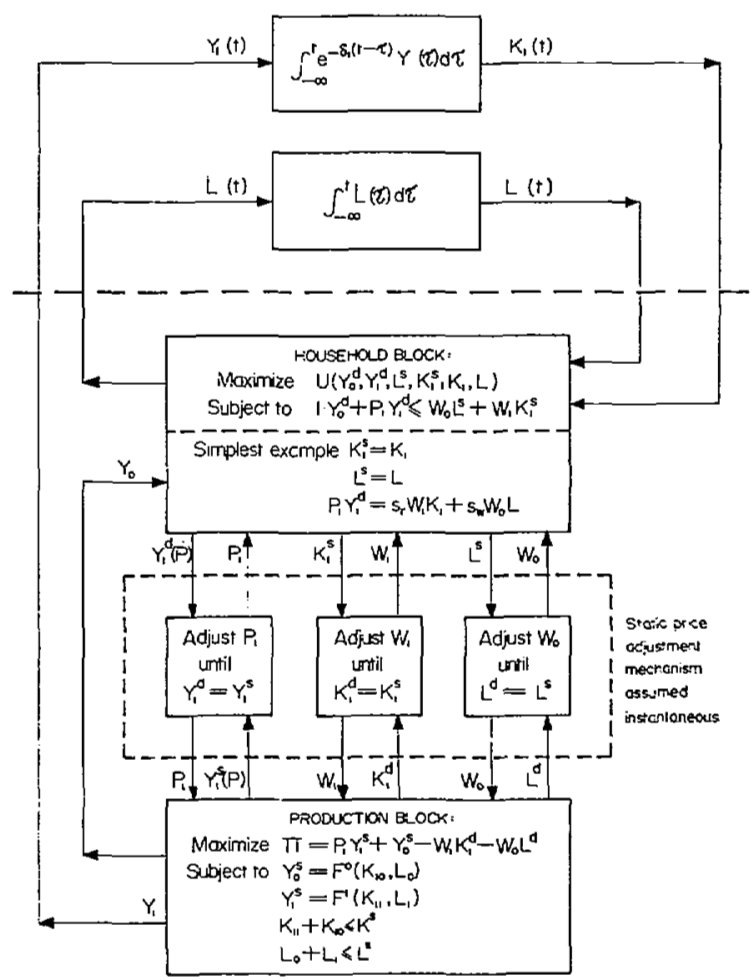

Fig. 1. Simplified flow diagram for economic model.

services, and for labor services. ${ }^{11}$ On each market a price is defined for the flow of goods, the flow of capital services, and the flow of labor services, respectively. Taking the price received for his output and the prices paid for rental of equipment and labor services, all as given, each firm's manager decides, in the light of his technological capacity, on the amounts of inputs it is appropriate for him to purchase and the amounts of output he shall produce. Because of the intervention of the price mechanism, it is unnecessary and irrelevant for him to ask who wants his product or what they want. All such relevant information is summed up in the price he treats as a parameter; likewise, all relevant information on the supply of inputs is contained in the prices for these. Thus the firm enters the goods market as a supplier of output and the market for services as a demander of labor or machinery services. ${ }^{12}$

On the other hand, households, facing the same prices, decide on what services they will offer, thus determining their income, and on what goods they will buy. Again, the price quotations contain all the information necessary and thus permit complete separation of household decisions from firm decisions. ${ }^{13}$ Unless the resulting decisions of all firms and all households are jointly consistent, the price quotation must be adjusted. (Clearly, it is a nice question to determine the conditions under which the existence of any equilibrium price vector is guaranteed and the mechanisms under which convergence to the equilibrium price vector would be assured. For reference to such discussion see Debreu [19], Arrow, Block, and Hurwicz [5], and a slightly less technical treatment by Kuenne [49].)

The simplifying assumption which is crucial to almost all growth models is that the system is always in static equilibrium in the sense that prices are always at the values which clear all markets described in Fig. 1. That is, it is assumed, in a sense, that it is legitimate towork as if time could be stopped, with no transactions taking place and no growth of assets, until the price adjustment process within the blocks labeled static price adjustment in Fig. 1 has converged to the

11 These markets are shown in Fig. 1 in the dashed inner block labeled static

price adjustment. block. bold block. 


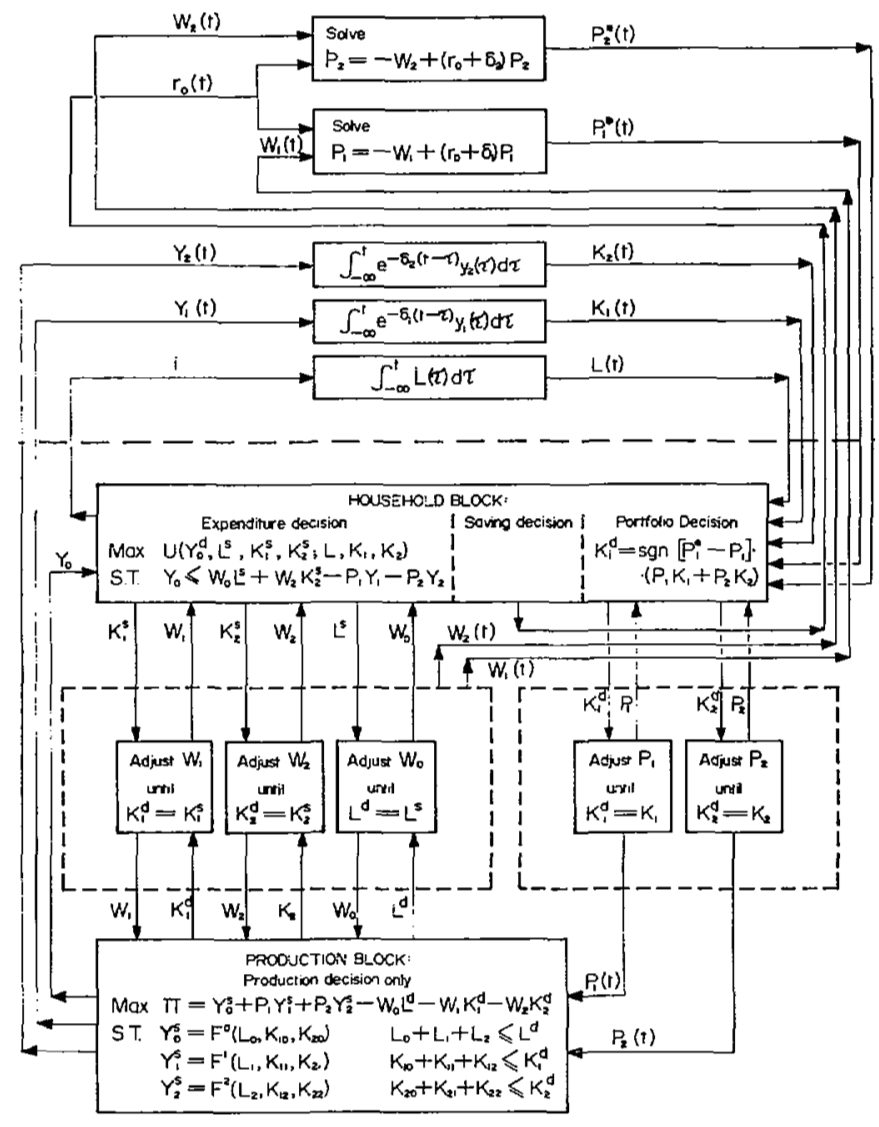

Fig. 2. Flow diagram for economic model with two durable traded assets.

momentary solution. It is this assumption that enables the growth theorist to treat "equilibrium dynamics" (see Habn [32]) in concentrating on long-run evolution of the system rather than short-run market adjustment.

In most early growth models, as in the simple example developed above, this problem of momentary equilibrium was trivially solved. Assuming that households offer all available capital and labor for production, the amount of output is determined and only the distribution of output between consumption and investment remains at issue. Letting prices for capital and labor services settle at whatever rates absorb available supplies and specifying the saving rate $s$ completes determination of the momentary equilibrium, and attention then focuses on the growth of assets, represented by the portion of Fig. 1 above the dashed line. More recent work, however, has dealt with models which produce distinct goods in distinct sectors of the economy, and in such cases the problem of allocating available resources between different uses and determining the output flows of all products entails consideration of a fairly large nonlinear programming problem (or at best a nonlinear simultaneous equations system).

One further issue demands brief comment. It has long been recognized that markets for durable assets (capital markets) differ from markets for flows of good and services precisely because such markets involve traders required to hold assets. In a model with one capital good this causes no trouble because there is only one kind of durable good, only one store of value which can be held. In more recent growth models with many distinct capital goods or with money and other financial assets as well as capital goods, there are different ways to hold assets, and decisions must be made as to appropriate portfolios to be held and appropriate holding periods for items in the portfolio. The standard argument (see Hotelling [39], and Samuelson [76]) has been that, in a perfect capital market, if there were a yield or discount rate $r_{0}(t)$ specified at each time $t$, then an asset with a current earnings flow $R_{i}(t)$ at time $t$ would in principle command a price equal to the present discounted value

$$
p_{i}^{*}(t)=\int_{t}^{T^{r}} R(\tau) e^{-\rho(t, \tau)} d \tau+S(T) e^{-\rho(t, T)}
$$

where

$$
\rho(t, \tau)=\int_{t}^{\tau} r_{0}(s) d s
$$

and $S(T)$ is some serap value at the terminal date $T$. Assuming a zero scrap value and differentiating, one finds that this perfect asset price should change over time in such a way that

$$
\dot{p}_{i}^{*}(t)=-R(t)+r_{0}(t) p_{i}^{*}(t)
$$

This basic "zero profit" relationship says that capital gains or losses should always be such that the total return (current earnings plus rate of price change) is neither more nor less than the imputed interest return on the asset value $p_{i}{ }^{*}(t)$. Unless the preceding differential equation were satisfied for all assets in the system, traders would presumably be attempting to dispose of those assets with lower yield in exchange for those with higher. Existing stocks of all assets are voluntarily held only when all of these differential equations are satisfied. ${ }^{14}$

It may be noted in passing that these conditions are appropriate only when concerns about liquidity, transactions costs, and so on can be ruled out. Introducing a more satisfactory portfolio theary into the analysis at this point would entail treating a grow th model with important stochastie components; this topic is an open research problem.

Fig. 2 sets out the structure of one possible model in which capital markets are important. The basic market structure for services of capital goods and labor and for distribution of nondurable consumer goods remains unchanged; what is added is a portfolio decision for households (it makes little difference to introduce portfolio decisions for firms as well) and a recognition that the saving decision of households may determine the currently acceptable yield $r_{0}(t)$. As before, if this saving decision is considered as subject to influence, then the control variable may be viewed as determining the yield $r_{0}(t)$. But it should be noticed that then the planner must take the price equations as given; control would be limited to choosing a value for $r_{0}$ at each instant and initial conditions $p_{2}{ }^{*}(0)$ to begin.

In Fig. 2, as before, the decision of the firm is represented by the block labeled production block. Information inputs into this block are the prices $W_{0}, W_{1}, W_{2}$, established for services of productive factors, and the prices $P_{0}$ (by convention set at unity), $P_{1}, P_{2}$, established for the goods produced. The firm then determines the actual inputs of productive factors and the actual output of goods, so as to make expected profits a maximum. The prices $W_{0}, W_{1}, W_{2}$ are themselves established, as before, on a market (enclosed in dashed lines in Fig. 2) to which households offer factor services according to the household expenditure decision and from which firms demand these services. The prices $P_{1}$ and $P_{2}$, on the other hand, are established on capital markets by the condition that prices must be such that all asset stocks must be willingly held. For this condition to hold, the prices $P_{1}$ and $P_{2}$ must coincide with the perfect asset prices $P_{1}{ }^{*}$ and $P_{2}{ }^{*}$ computed according to the differential equations at the top of Fig. 2. When this coincidence is attained, the household portfolio decision has established the prices $P_{1}, P_{2}$, taken as data by the firm. The household saving decision may then be thought of as determining the instantaneous yield or return on assets $r_{0}(t)$, which is necessary in the differential equations for $P_{1}$ and $P_{2 \text {. }}$ Given this yield $r_{\mathrm{o}}$, the

14 Again note the implicit assumption that time can be stopped while these capital markets adjust fully to the ideal values defined at each time $t$. There is room for research into properties of growth models where complete adjustment is not achieved before the system moves on. The differential equations are thus derived as a deseription of a market pracess, not as a condition that any single criterion be optimized (although, of course, the market process itself reffects individual optimizing behavior in portfolio management). Nevertheless it will turn out that these descriptive equations in many cases coincide with the EulerLagrange equations in an optimizing problem. It is in this important sense that Samuelson's dynamie efficiency conditions [76a] extend the principle of the avisib hand from statie esonibing equilibrium on a market governed by individual attempts to maximize the value of individual portfolios coincide with a subset of the necessary conditions for 
rentals (prices of factor services) $W_{1}$ and $W_{2}$, and the existing prices $P_{1}$ and $P_{2}$, the differential equations at the top of Fig. 2 are complete. Given the output flows $Y_{1}$ and $Y_{2}$ established by the firm, the remaining differential equations governing the growth of asset stocks are also complete, and the long-run evolution (governed by the equations displayed above the dashed line in Fig. 2) of the system is fully determined.

The upshot of the preceding discussion is that one can often view optimal control problems in economics in the following summary way. Production theory, entailing at each moment efficient static allocation of existing resources, determines a set of feasible or attainable output vectors. Demand conditions, which will generally involve a number of control variables or instruments, serve to pick out a unique point from the attainable set. These demand conditions may be derived from some optimizing criterion, that is, the control variables may be selected in the light of some criterion purporting to represent individual or social welfare. Obvious questions arise: Is there a unique positive equilibrium so determined? What kind of price mechanism or decentralized procedure could sustain the equilibrium? These questions, which have been studied at length in economic theory, properly belong to what might be called static economics. Growth theory in economics now builds on this material to investigate what kind of growth in stocks comes about as a result of the instantaneous equilibrium established. Until quite recently, growth theory was relatively simple because it suppressed almost all the structure connected with the determination of instantaneous equilibrium. But it is clear that as growth theory matures, all this hidden structure has to come back into view.

Thus, to summarize:

1) The static allocation problem enables all relevant variables to be written as functions of relatively few underlying "endowment" levels or levels of factor stocks. If, in an optimizing problem, the control variables were taken to include allocations of available resources to possible uses, then the maximization of the usual Hamiltonian expression would entail solution of this static allocation problem and might, therefore, involve solution of a large-scale nonlinear programming problem at each moment.

2) If a decentralized system is assumed, then the static allocation problem might be left to a market mechanism, with control being exercised only over saving rates or similar variables. In this case it must be recognized that the assumption that the static equilibrium configuration is achieved instantaneously at each moment is a crucial idealization.

3) If the decentralized system involves several distinct durable assets, then capital market trading will, in principle, bring about satisfaction of differential equations for asset prices which prove to be of the same form as the Euler-Lagrange equations for the state variables in the system. In this case control need not be exereised directly over rates of accumulation of each asset separately, but may be left to a market mechanism with profit-maximizing producers, provided only that a value $r_{0}$ is optimally selected at each instant and prices $p_{i}^{*}(0)$ are selected appropriately at the initial time. Again, the idealization that perfect asset prices are always maintained should be noted.

These observations may be illustrated with a few examples, to which the next section is devoted.

\section{Illustrative Examples}

Example 1: Solow Model [92] and Ramsey Problem [70]

Section II adopted a state-space description consisting of the vector $(K, L)$ and transition equations

$$
\dot{K}=s F(K, L)-\delta K, \quad K(0)=K_{0}
$$

(where the term $\delta K$ is added as a simplified provision for replacement and depreciation) and

$$
\dot{L}=n L, \quad L(0)=L_{0}
$$

subject to the control constraint

$$
0 \leq s \leq 1
$$

and the state-space constraints ${ }^{15}$

$$
0 \leq K, \quad 0 \leq L
$$

Study of this nonoptimizing model for various specified savings functions determining $s$ has been extensive. (See Solow [92], Swan [97], and many other references cited by Habn and Matthews [33].)

The problem of optimal economic growth in this context is to determine a saving policy which maximizes some performance index. The criterion function suggested in Section II is

$$
J=\int_{0}^{\infty} U(C / L) e^{-\rho t} d t
$$

where $T$ might be infinite and $\rho$ might be positive, zero, or negative depending on the decision as to whether "time preference" or population weighted utility is appropriate. One must, therefore, write $C$ in terms of the state variables by observing that if the only use of output is for consumption or for savings and $s$ is the fraction of output saved, then

$$
C=F(K, L)-s F(K, L)=(1-s) F(K, L)
$$

follows immediately. Thus one obtains the system

$$
\begin{gathered}
J=\int_{0}^{\infty} U[(1-s) F(K, L)] e^{-\rho t} d t \\
\dot{K}=s F(K, L)-\delta K \\
\dot{L}=n L
\end{gathered}
$$

where $\rho, \delta$, and $n$ are constants with $\delta$ and $n$ definitely positive. Transforming to per capita terms by introducing $k \equiv K / L$ and

$$
f(k) \equiv F(k, 1)
$$

yields

$$
\begin{gathered}
J=\int_{0}^{\infty} U[(1-s) f(k)] e^{-\rho t} d t \\
\dot{k}=s f(k)-(n+\delta) k \\
0 \leq s \leq 1, \quad 0 \leq k .
\end{gathered}
$$

For fixed $s$ and $p$, the integrand function and the Hamiltonian $H=$ $U[(1-s) f(k)] e^{-\rho t}+p[s f(k)-(n+\delta) k]$ are concave in $k$. This is a straightforward problem, solved by straightforward methods. There is no point here in going into the details, which can be found in Cass [11], [12], Koopmans [48], Ramsey [70], Samuelson [80], and Shell [87].

Analytical solution is generally not feasible, but complete information can be obtained from a phase diagram, which need not be drawn here. Introducing $q=p e^{\rho t}$, one may then write the two equation system

$$
\begin{gathered}
\dot{q}=(\rho+n+\delta) q-[(1-s)+s q] f^{\prime}(k) \\
\dot{k}=s f(k)-(n+\delta) k
\end{gathered}
$$

which has an equilibrium point $\left(k^{*}, 1\right)$, where $k^{*}$ is defined by $f^{\prime}\left(k^{*}\right)$ $=\rho+n+\delta$. When the utility function is linear, the point $\left(k^{*}, 1\right)$ represents a singular are along which the optimal control $s$ is not immediately determined by maximization of the Hamiltonian, but is determined by a condition that the system remain at the equilibrium point. It may be easily shown that the point $\left(k^{*}, 1\right)$ has saddle-point properties, and thus that, for any initial value $k^{0}$, there is a unique initial price $q(0)$ such that the system point satisfying the preceding equations converges to $\left(k^{*}, 1\right)$. Details of the analysis may be found elsewhere.

15 Since $n$ is assumed to be a positive constant, one could easily drop $L$ altogether from the state description, and for $L_{\theta}>0$, satisfaction of the last statespace constraint is guaranteed. (This observation justifies division by $L$ to place all variables in per capita terms, as will be done.) 
What are the interesting things about this problem? First, consider the time horizon and the question of transversality condition. When the horizon is infinite, but $\rho$ is positive and $U(c)$ is bounded above on any feasible path, then the integral converges and it is observed that the price variable tends to zero in the limit (as one might expect by analogy with transversality conditions for the finite horizon case). When $T$ is infinite and $\rho$ is zero, the integral diverges, but it is possible to show that

$$
\int_{0}^{\infty}\left[U((1-s) f(k))-U\left(\left(1-s^{*}\right) f\left(k^{*}\right)\right)\right] d t
$$

has a finite upper bound and that, therefore, a ranking may be based on the measure of divergence from bliss (the maximum sustainable utility level $U^{*}$ ). One observes in this case that prices do not tend to zero. (See Koopmans [48].) When $T$ is infinite and $\rho$ is negative, the integral diverges and the criterion $J$ yields no satisfactory ordering. In this case one may go over to a partial sum criterion of the sort studied by Weizsäcker [105], Gale [29], and McFadden [59] and deseribed in the preceding.

For cases in which the horizon is infinite, then, the question as to appropriate terminal conditions seems open in general, although in particular problems it is possible to show that vanishing of the value of the terminal capital stock is a necessary condition for optimality.

For finite horizon problems, the difficulty is simply that there is no natural stopping time and no natural set of terminal conditions to impose. (See the discussion by Chakravarty [16] and Maneschi [57].)

The second interesting feature illustrated by this first example is the characteristic form of the solutions which emerge. Because of the saddle-point equilibrium, the optimal paths display a catenary or "turnpike" property which has greatly fascinated economists. One version of this catenary property is worked out in the author's dissertation [21a] and the entire problem is worked out in detail in Samuelson [78], [80] and Cass [11], [12]. The original turnpike conjecture is due to Dorfman, Samuelson, and Solow [26]; its mathematical significance is discussed in Inada [42].

Finally, an interpretation of the auxiliary yariable is interesting to the economist. On economic grounds one can argue that the current earnings of a capital good must settle at the net value of an extra unit of machine service, so that earnings of the capital good in this example can be written as

$$
R(t)=\alpha(t) F_{K}(K, L)=\alpha(t) f^{\prime}(k)
$$

where $\alpha(t)$ is the value of a unit increase in the flow of output. If one were to take the consumption good as the standard of value, measuring all prices in units of the consumption good, and to assign to the capital good an imputed price $q(t)$, measured also relative to the consumption good as standard, then it could be argued that the value of an increase in the flow of output (which is split in the proportions $s, 1-s$ between capital goods and consumption goods) ought to be simply the weighted average

$$
\alpha(t)=(1-s) \cdot 1+s q(t)
$$

With this interpretation, it can be seen that the differential equation satisfied by the auxiliary variable $q(t)$ is identical to the capital market trading condition satisfied by the perfect asset price $p^{*}(t)$ described in Section III. ${ }^{16}$

\section{Example 2: Two-Sector Model}

Example 1 focused on the question of how much the community should save; the production specification was artificially simplified by 16 In the case of the linear utility function, the interpretation can be fairly
direct since it makes sense to measure all variables, including auxiliary variables, in physical units. When the utility function is not linear, the auxiliary variable takes on units of marginal utility (that is, of the derivative of the utility function), which is not constant. Nevertheless, the interpretation is helpful in suggesting the nature of optimal trajectories and permits one to think of the maximum principle as a technique for determining the appropriate asset prices which transform the entire intertemporal maximization problem into a static maximization problem which might be solved by competitive markets, once suitable terminal conditions have been established. the assumption that one could in the model simply divide the output flow between investment and consumption, as if output were a single homogeneous commodity. More realistically, the division is accomplished by diverting resources from one sector to the other, and some resources might be well adapted to only one use. Recognition of this fact entails considering an economy with two distinct sectors and imperfect transferability from output of one to output of the other. In this case there is still a single state variable $k$, but there are several additional variables associated with the determination of instantaneous equilibrium. Leaving all details of the derivation to Uzawa [104] and Shell [87], we may write the system equation in per capita form as

$$
\dot{k}=f_{1}{ }^{\prime}\left(k_{1}\right)\left(s_{r} l i c+s_{s} \omega\right)-n k
$$

where now $k_{1}$ and $\omega$ are components of the solution vector $x$ to a set of equilibrium conditions

$$
\psi(x ; k)=0
$$

to be satisfied at all times and $s_{r}, s_{w}$ are controls. Written explicitly, the system is

$$
\begin{aligned}
& \text { 1) } \frac{f_{1}\left(k_{1}\right)}{f_{1}^{\prime}\left(k_{1}\right)}-k_{1}-\omega=0 \\
& \text { 2) } \frac{f_{2}\left(k_{2}\right)}{f_{2}^{\prime}\left(k_{2}\right)}-k_{2}-\omega=0 \\
& \text { 3) } \sigma k_{1}+(1-\sigma) k_{2}-k=0 \\
& \text { 4) } \sigma f_{1}\left(k_{1}\right)-f_{1}^{\prime}\left(k_{1}\right)\left(s_{r} k+s_{1 \sigma} \omega\right)=0
\end{aligned}
$$

where $0 \leq \sigma=L_{1} / L \leq 1$ is the fraction of the labor force assigned to the first sector, which produces investment goods. Constraints 3 ) and 4) represent market clearing conditions, while 1) and 2) represent necessary conditions for the maximization of the appropriate Hamiltonian $H$ when $k_{1}, k_{2}$, and $\sigma$ are considered control variables chosen subject to 3 ) and 4), and to non-negativity constraints on all variables.

The criterion to be maximized is

$$
J=\int_{0}^{\infty}(1-\sigma) y_{2} e^{-\gamma t} d t
$$

The point of this example is only to illustrate that, as was remarked in Section III, the complex character of the momentary equilibrium will generally mean that the maximization of the Hamiltonian at each moment is a nontrivial problem in concave programming.

\section{Example 3: Two Capital Goods Model}

Examples 1 and 2 both illustrate models which contain only one durable good and which, therefore, involve no capital market trading. The present example deals with two distinct capital goods, labeled (in per capita form) $k_{1}$ and $k_{3}$, and, therefore, must deal somehow with capital market equilibrium conditions (auxiliary equations) as a part of the complete descriptive system to be optimized.

Letting subscripts on $f$ now denote partial differentiation, define

$$
c=f\left(k_{1}, k_{2}\right)-k_{1} f_{1}\left(k_{1}, k_{2}\right)-k_{2} f_{2}\left(k_{1}, k_{2}\right)
$$

(which already incorporates some nonoptimizing saving behavior) and let the system equations be

$$
\begin{aligned}
& \dot{k}_{1}=\sigma\left(k_{1} f_{1}+k_{2} f_{2}\right)-\lambda k_{1} \\
& \dot{k}_{2}=(1-\sigma)\left(k_{1} f_{1}+k_{1} f_{2}\right)-\lambda k_{2} .
\end{aligned}
$$

Determine the control $\sigma$ so as to maximize

$$
\int_{0}^{\infty} c(t) e^{-\rho t} d t
$$

This problem, which is drawn from Shell and Stiglitz [88], is structurally little different from Example 5 . The feature which is of interest at the moment is only that the optimal control in this case must involve auxiliary variables $p_{1}$ and $p_{2}$ such that if 


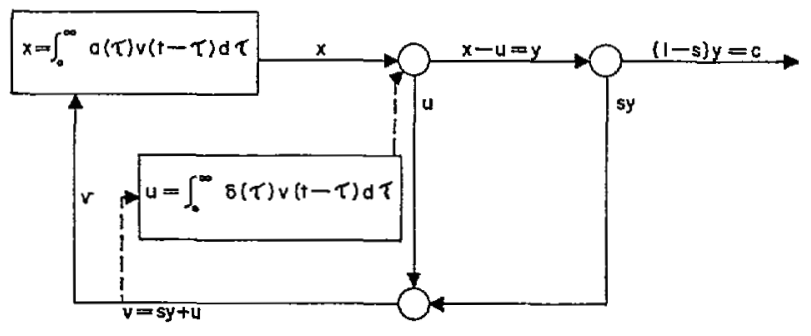

Fig. 3.

$$
\begin{array}{ll}
p_{1}>p_{2}, & \sigma=1 \\
p_{1}<p_{2}, & \sigma=0 \\
p_{\perp}=p_{2}, & \sigma \in[0,1] .
\end{array}
$$

Since the auxiliary variables $p_{1}$ and $p_{2}$ in fact correspond to (ideally) observable market prices, one could imagine realizing a decentralized control through a market which satisfied $\sigma=U\left[p_{1}-p_{2}\right]$, where $U$ is a unit step. This is in principle precisely what a competitive market for capital goods is supposed to do. Yet if one substitutes $\sigma=U\left[p_{1}-\right.$ $\left.p_{2}\right]$ in the system of the preceding two differential equations together with the usual equations governing the auxiliary variables, the system becomes unstable in the sense that arbitrary initial prices will lead ultimately to the worst rather than the best of all possible worlds. ${ }^{17}$ Only a transversality condition related to some distant terminal date can rule out assignment of the arbitrary initial prices leading away from equilibrium; Shell and Stiglitz [88] attempt to determine whether a competitive system has any natural way to guarantee satisfaction of such transversality conditions. The matter is further discussed by Kurz [50] and Hahn [109].

\section{Example 4: Reneroal Model}

The preceding examples largely ignore the question of timing of returns from investment. More detailed analysis of investment projects, however, emphasize this issue, in part because reinvestment of intermediate cash throw-off is an important source of financing in itself. To illustrate this kind of question, drawn more from microeconomics than growth theory itself, consider a possible extension of a renewal model studied by Chipman [18]. The system may be illustrated as follows. (See Fig. 3.)

From gross output $x$ is deducted a depreciation charge $u$. From the remainder $y$ is deducted a saving $s y$. The remainder $(1-s) y=c$ is available for consumption. The two deductions are pooled to obtain a sum $v=s y+u$ available for reinvestment. Gross output $x$ and the depreciation charge $u$ depend on all past investments as shown. Let

Problem: Let $a(t)$ be a given function such that $0<\int_{0}^{\infty} a(t) \mid d t<\infty$.

$$
J=\int_{0}^{\infty} e^{-r t} c(t) d t
$$

where $c$ is defined as before. Then determine the functions $s(t), \delta(t)$, so as to yield a maximum for $J$. As subsidiary problems, if either $s(t)$ or $\delta(t)$ be arbitrarily given, determine the optimal form for the other.

The point of this example is that renewal or vintage models may require the economist to go to methods which do not depend on the possibility of a finite-state representation. See also Levhari and Sheshinski [54].

\section{Example 5: Training Costs Associated with a Nonproduced Factor}

Dobell and Ho [22] give a solution to one version of a model where there may be unemployment and costs to hiring or training labor.

17 If one adds the auxiliary differential equations and this control rule to the system, but fails (as the market might fail) to add the transversality condition appropriate to "shadow" prices, taking instead initial values historically given for market prices, then the sy'stem in general diverges from its saddle-point equilibrium. This abservation was first explicitly made by Hahn [31].
An obvious extension is to admit the finite time lag in training as well as the resource cost of training. This, of course, entails solution of systems of differential difference equations, but such extension may be helpful in dealing satisfactorily with some of the fascinating questions involved in optimal allocation of resources for investment in education or lesearch, where gestation lags may be crucial.

\section{Example 6}

Consider as a final example a case in which there is a delay, but of a smoother type. Such a problem, which might be referred to as a problem of indirect control, is illustrated by the following:

$$
\operatorname{maximize} J=\int_{0}^{\infty}(1-\sigma) f(k) e^{-\gamma t} d t
$$

subject to

$$
\begin{array}{ll}
\dot{k}=\sigma(R) f(k)-n k, & k_{0}=k(0) \\
\dot{R}=\mu \cdot(r-R), & R_{0}=R(0) \\
\dot{r}=u, & r_{0}=r(0) \\
0 \leq u \leq 1, \quad 0 \leq r, \quad 0 \leq R
\end{array}
$$

where $\sigma$ is a given smooth function; $f(k)$ is the usual well-behaved per capita production function; $\gamma, n$, and $\mu$ are positive constants; and $u$ is a control variable. The problem here, of course, is that the control $u$ is "far away" from the important state variable $k$. In a preliminary paper [23] on this problem, Dobell and Ho suggest that the optimal trajectory may require switching infinitely fast. In some computed examples with a smoothed version employing a penalty function on $u$ rather than inequality constraints, an oscillatory solution is demonstrated. Interesting extensions to cases where there may be error in implementing control or imperfect observation of present state are obvious.

\section{Concluding Comments}

It is silly to spend much time speeulating about future applications of control theory in economics; unexpected new directions will undoubtedly emerge. But this quick survey might suggest a few of the issues likely to be of interest.

1) The technical question of the transversality conditions necessary in a free endpoint problem with infinite horizon seems yet to be fully resolved.

2) Selection of an appropriate intertemporal welfare function will continue to be a challenge.

3) Renewal or vintage models in economics lead to a class of problems different from the usual problems with finite state space discussed previously. Perhaps recent work on programming in linear spaces will prove relevant here, but the apparent restriction thus far to linear systems is stringent-probably fatal-in most economic applications.

4) The introduction of lags, through "double integrators" or related higher order systems, will lead to problems in which the optimal control is oscillatory, and this result should lead to further elaboration of political and economic costs involved in frequent changes in control variables themselves. Problems where time delays depend on control variables or on parameters to be optimally selected also arise naturally in the study of public investment decisions.

5) Turning from the so-called one-sector model to a two-sector one capital good model, one finds nothing particularly new in the character of the optimal paths, but already sees a hint of computational difficulties which may be crucial as numerical work proceeds. These difficulties arise because the static equilibrium configuration, for given values of state and auxiliary variables, is obtained by solution of a system of nonlinear simultaneous equations. Equivalently, maximizing the Hamiltonian involves the solution of a nonlinear programming problem at each moment. Perhaps, because of continuity considerations, the solution from one instant, stured, will prove a good starting point for an iterative computation at the 
next instant. But in any case, it seems that numerical solution must involve step-by-step integration with solution of a (possibly large) constrained maximization problem at each step, the step size itself being taken small near points of discontinuity in the controls. Kendrick and Taylor [45] are tackling some of these problems in work on numerical methods for economic models.

6) Mloving from the two-sector to the two capital good model, one encounters fascinating questions about the significance of price behavior. In contrast to the usual control problem, the economist thinks naturally in terms of realizing control through the auxiliary variables or prices. A true feedback control implies centralized direction of the system; almost any scheme for decentralization depends preeisely on computing values for the auxiliary variables and requiring the system to respond to these. For the economist, indeed, this is precisely the decentralization which can, in some cases at least, be achieved through competitive markets. But then, without perpetual recomputation of prices in the face of shocks, the decentralized system will show unstable development. Since the whole question of the effectiveness of, and means to realize, decentralized control in large syste ns is very topical just now, this issue may have significance outside economics.

Moreover, these considerations emphasize that the "plant" which the economist studies may include the usual auxiliary equations as a part of the system. That is, optimizing behavior by individuals with respect to portfolio decisions may force asset prices to satisfy the auxiliary (Euler-Lagrange) equations, bringing yields on all assets into equality. Once the common yield is itself determined (perhaps by the condition that total resources offered for investment by households match total resources demanded for capital formation by firms), then the determination of asset prices is complete (given initjal conditions). Profit-maximizing decisions by producers realize the optimum composition of output and thus satisfy the requirement that the Hamiltonian be maximized at each instant.

Under these circumstances, control by an economic planner is limited to influencing the common yield on assets (by offering some other security as an alternative store of value, bringing saving or investment into line through tax policies, or by operating directly on saving or investment desires), and perhaps to establishing initial asset prices consistent with the appropriate transversality conditions.

At any rate, the point is that the economic planner may have to take as given both the usual system equations and the usual EulerLagrange auxiliary equations, and initial conditions for each, as well as a side condition which already maximizes $H$ with respect to production decisions. Only relatively few undirect control variabies, and pcrhaps some parameter optimization, remain to provide a channel for it flueneing the economy. (Perhaps in the United States this will be thought to be just as well.)

7) Without elaboration, we can observe that the preceding considerations give a prominent role to decisions of portfolio theory. But portfolio problems make little sense except in an explicitly stochastic context; bence, even abstracting from problems of errors in observations of state or in implementation of control (which one probably should not do anyway), problems of stochastic control will be central in economic applications to come.

8) Finally, this discussion displays one common theme in looking at various consequences of the fact that economic systems involve extensive conscious decision making. In part, this fact simplifies the realization of optimal control because, by Adam Smith's prineiple of the invisible hand, individual decisions made in the light of selfinterest also help to maximize $H$ at each instant, and trading of assets on capital markets helps to bring about satisfaction of Samuelson's dynamic efficiency conditions, which are also the auxiliary equations of Pontryagin. But letting the system take matters into its own hands has its dangers: if initial price quotations are wrong, it is unclear when the market has to face up to that fact, and divergence toward a stable minimum rather than a saddle-point maximum may result. Moreover, conscious decision making by components of the system will result in responses to control which act to cushion the effect, to insulate each component as much as possible from the control.
The effectiveness of control may be reduced, therefore, and the controllability of the system may itself come into question.

These considerations, particularly of the dual-stability feature inherent in the decentralized system, give impetus to the search for control rules which may depart a little from optimality, but which are robust and stable in the face of minor shoeks or errors and which may relieve Congress of the need to implement new tax policies infinitely quickly or infinitely often.

There are many other extensions currently under study: introduction of the notion that technical improvement is generated within the system in various ways (see Uzawa [103] for one example); introduction of a labor force structure and a finite training time for labor, leading to formulation of control problems with time delays; study of systems in which control is incomplete or very indirect; introduction of uncertainty either in observation of the state or implementation of control; and so on. Applications in microeconomics to saving and portfolio decisions of the individual consumer or to investment and other operating decisions of individual firms, or applications of the theory of differential games to problems of bargaining and economic rivalry have not been emphasized, but certainly should not be overlooked. The list is long, but perhaps this discussion illustrates the kinds of intriguing control problems economists may be talking about when the presidential campaign of 1972 rolls around.

\section{ACKNOWLEDGMENT}

The author is grateful to the members of the Control Theory Seminar for their thoughtful comments and to E. Burmeister and Y. C. Ho for a number of additional ideas.

\section{REFERENCES}

[1] K. J. Arrow. "Applications of control theory to economic growth," Institute for Mathematical Studies in the Social Sciences. Stanford University, Stanford, Calif., Tech. Rept. 2, July 14, 1967.

[2] K. J. Arrow and G. Debreu, "Existence of an equilibrium for a competitive economy," Econometrica, vol. 22, pp. 265-290, 1954

[3] K. J. Arrow and L. Hurwicz, "On the stability of competitive equilibrium, pt. I," Econometrica, yol. 26 , pp. 522-552, 1958.

[4] K. J. Arrow, "Optimal capital policy, the cost of capital, and myopic deci

Sion rules," Ann. Inst. Stat. Math., vol. 16, pp. 21-30, 1964.

[5] K. J. Arrow, H. Block, and L. Hurwicz, "On the stability of competitive equilibrium, pt. II," Econometrica, vol. 27, pp. 82-109, January 1959.966.

6] M. Athans and P. Falb, Optimal Control. New York: McGraw-Hill. I966, Pe. K. Bardhan, "Optimum accumulat

[8] R. Bharadwaj and T. Manoharan, "On the theory of optimal savings with finite planning horizon," Sotthern Econ. J., October 1966.

[9] J. Black, "Technical progress and optimum savings," Rev. Econ. Stud. vol. 29, June 1962.

[9a] C. J. Bliss, "On putty clay," Rev. Econ. Stud., pp. 105-132, April 1968. dell. 1969 .

[11] D. Cass. "Optimum economic growth in an aggregative model of capital accumulation," Rev. Econ. Stud., vol. 32 , pp. 233-240, 1965.

[12] 2aptimum growth in an aggregative model of capital accumulation:

a turnpike theorem" "Econometrica, vol. 34, October 1966.

[13] S. Chakravarty. "The existence of an optimum savings program." Eco-

[14] nometrica, vol. 30 , pp. $178-187$. January 1962 .

[15] - "Optimal investment and technical progress," Rev. licon. Stud., vol. 31, pp. 203-206, June 1964

[16] 31 , "Optimal savings with finite planning horizon: a reply," Internat' Econ. Rev., rol. $\overline{1}$, pp. 119-123, January 1966.

[17] A. Charnes, J. Dreze and M. Miller, "Decision and horizon rules for stochastic planning prohlems: a linear example," Econometrica, vol. 34, pp. $307-330$, April 1966 .

[18] J. Chipman, "The rate of growth and the internal rate of return." presented at the Econometric Society Yeeting. Toronto, Ont.. Canada. August 1967 .

[19] G. Debreu, The Theary of Value. New York: Wiley, 1959

20] J. Desrousseaux, "Expansion stable et taux d'interet optimal," Ann. Mires, November 1961 .

[21] P. A. Diamond, "The evaluation of infinite utility streams." Econometrici, vol. 33 , January 1965 .

[21a] A. R. Dobell, "Training costs, heterogeneous labor, and simple capital models." Ph.D. dissertation, Massachusetts Institute of Technology,

[22] A. R. Dobell and Y. C. Ho, "Optimal investment palicy: an example of a control problem in economic theory," IEEE Tranis. Automatic Control, vol. 1C-12, pp. 4-14, February 1967

23] - "Optimal policy with indirect control," presented at the Econometric Society Meecing, Toronto, Ont., Canada, August 1967

[23a] J. S. Duesenberry, G. Fromm, L. R. Klein, and E. Kuh, Eds., The Brool:ing: Quarterly Econometric Model of the Lnited States. Chicago: Rand MeNally,

24] A. I. Egorov, "Optimal control in Banach spaces," Muth. Sys. Theory, De25] R. Dor $196 \pi$

Iman, The Price System. Englewood Cliffs, N.J.: Prentice-Hall, 1964.

26] R. Dorfman, P. A. Samuelson, and R. M. Solow, Linear
Economic Analysis. New York: McGraw-Hill, 1958.

[2] H. El-Hodiri Anals. New York: McGraw-Hill, $1958 . \quad$. Nrannert Graduate School of Industrial Administration, Purdue Lniversity, Lafayette, Ind., Inst. paper 127, 1966. 
[28] R. Findlay, "Optimal investment allocation between consumer goods and capital goods," Econ. J., vol. 76, pp. 70-83, March 1966 .

[29] D. Gale, "On optimal development in a multi-sector economy" Rer. Econ [30] Stud.; vol. 34, pp. 1-18, January 1967.

[30] S. Goldman, "Optimal growtb and continual planning revision," Rev. Econ. Stud. vol. 35, pp. 145-154, April 1968.

[31] R. W. Goldsmith, "A perpetual inventory of national realth," in Studies in Income and Wealth, vol. 14. New York: Nat'l Bureau of Economic

[32] F. H. Hahn, "The stability of gronth equilibrium," Quart. J. Econ., vol.

[33] F. H. Hahn and R. Matthews, "The theory of economic growth: a survey,"

in Surveys of Economic Theory. New York: St. Martin's, 1965

[34] F. H. Hahn, "Equilibrium growth with heterogeneous capital goods,"

35] W. Haque, "A pol. 71, November 1966.

T. Haque, "A pseudo-classical dynamic programming model of capita

[36] - , "Dynamic programming in a multi-produet model of economic de-

velopment," Internat'l Econ. Rev., vol. 7 , January 1966.

linear "Intertemporal optimality and Von Neumann equilibrium in nonlinear activity analysis: corrections" Metroeconomica, yol. 17, pp. 45-46,

[38] C. Holt, "Linear decision rules for economic stabilization and growth," Quart. J. Econ., pp. 21-45, February 1962.

[39] H. Hotelling, "A mathematical theory of depreciation," J. Am. Stat. A ssoc.,

1925 . Houthakker "The present state of consumption theory"

metrica, rol. 29 , p. 704,1961 .

[41] - " "Revealed preference and the utility function," Economica, new

42] Ker., Vol. 17 . May 1950 .

Econ. Stud., vol. 31 , I964.

- On a two-sector model of economic gromth: comments and a

generalization," Rev. Econ. Stud., vol. 30, June 1963.

De Econamicst "second golden rule essay'."

45] D. Kendrick, and L. Thy. "Numerical methods 1966.

ing models for economic planning," Harvard Institute for Economic Research, Cambrdge, Mass., Discussion paper 8. January 1968.

[16] T. C. Koopmans, P. A. Diamond, and R. E. Williams. "Stationary utility

- and time perspective," Econometrica, vol. $32,1964$.

47] T. C. Koopmans, "Stationary ordinal utility and impatience," Econo

Development Planning. Chicago: Rand McNally, 1966 .

[49] R. E. Kuenne, Mieroeconomic Theory of the Market Mechanism. New York: Macmillan, 1968.

[50] M. Kurz, "The general instability of a class of competitive gronth pro-

51 cesses," Rev. Econ. Stud., vol. 25, pp. 155-174, April 1968 .

Fork: Wiley, $196 \overline{7}$.

[52] Work: Wiley, 1967

ed. New York: Oxford, 1951. of the American Economy 1919-19s9, 2nd

[53] A. Lerner, "Consumption-loan interest and money," J. Politicul Econ.,

[54] D. Levhari, and E. Sheshinski, "On the sensitivity of the level of out put to savings: embodiment and disembodiment," Quart. $J$. Econ., vol. 81 ,

August 1967

E. Malinvaud, "Croisssaces optimales dans un modele macroeconomique,"
in The Econometric A pproach to Development Planning. Chicago, Ill.: Rand AcNially, 1966.
," "Les croissances optimales," Cahiers du Saminarie d'econmetric,

[56] no. 8. "Les croissances optimales," Cahiers du Saminarie deconmelric,

[5i] A. Maneschi, "Optimal savings with finite planning

[58] " "Optimal savings with finite planning horizon: a rejoinder," In-

9 ]

Research in Management Science Uevelopment programs," Center for Working paper 173 , June 1966.

[60] J. Mirrlees, "Optimal growth when technology is changing." December 1965 (unpublished).

[61] - "Optimum accumulation under uncertainty," Econometrica (to be

[62] I. F. Pearce, "The end of the golden age in Solovia," Am. Econ. Rev., vol.

[63] E. S. Phelps, "The golden rule of accumulation: a fable for growthmen,"

Am. Econ. Rev., vol. 51, September 1961.

[64] $\frac{A}{1}$ "The end of the golden age in Solovia: comment," Am. Licon. Rev.,

65] vol. 52,1962 . Golden Rules for Growth. New York: Norton, 1966.

[66] - "Second essay on the golden rule of accumulation," Am. Econ.

[07] Rev., "vol. 55 , pp. $793-814$, September 1965 .

Cowles Foundation, Yale University, New Haven, Conn., Discussion paper $19-1,1965$.

[68] J. P. Powelson, Economic Accounting. New York: MeGraw-Hill, 1955.

[69] R. Radner. "Optimal growth in a linear-logarithmic economy," Inter-

nat" Econ. Rer.. vol. 7 , 1966

[10] F. P. Ramsey, "A mathematical theory of savings," Econ. J., vol. 38

i1] I. Pichter, "Revealed preference theory," Econometrica, vol. 34, p. 635, Juiy 1966.

neoklassischen liachistumtheorie," Kyklos, vol. 1\%, pp. $40-64,1964$ Abstract in J Econ. Abstracts, p. 336, July 1964.

[i3] J. Robinson, "A neo-classical theorem," Rer. Econ. Stud., vol. 29, 1962.

1] P. A. Samuelson, Foundatione of Economic Analysis, Cambridge, Mlass.

Harvard University Press, $194 i$.

[D] - "Consumption theory in terms of resealed preierence." Economicu

(6] new ser.. vol. 15, November $19+8$.

[76a] _- "Efficient paths of capital accumulation in terms of the calculus of variations," in Mathematical Methods in the Sociul siences, $\mathrm{K}$. J. Arrow, S. Karlin, a
Press, 1959 .

[ī] - "An exact consumption loan model with or without the social contrivance of money," $J$, Political Econ., pp. $46,-482$, December 1958 .

[78] - - "The two-part golden rule deduced as the asymptotic turnpike of catenary motions," Western Econ. J., vol. 6, March 1968

[79] - . "The fundamental singularity theorem for non-joint production," Internat'l Econ. Rev., vol. 7, pp. 34-41, January 1966.

[80] - - "A catenary turnpike theorem," Am. Econ. Ret., vol. 55, 1965.
[81] P. A. Samuelson and R. M. Solow, "A complete capital model involving heterogeneous capital goods," Quart. J. Econ., vol. 70, pp. $537-562$,

[82] J. K. Sengupta, "Truncated decision rules and optimal economie growth with a fixed horizon," Internat'l Econ. Rev., vol. 7, pp. 42-64, January 1966. "On the relative stability and optimality of consumption in ag84 ] J. K. Kengrive growth models," Economica, vol. 31, F ebruary 1964.

J. K. Sengupta and G, Tintner, "The flexibility and optimality of Domar
type growth models," Metroeconomica, vol. 17, pp. 3-16, July-August

[85] K. Shell, "Toward a theory of inventive activity and capital accumulation," Am. Econ. Rev., vol. 56, pp. 62-68, May 1966 .

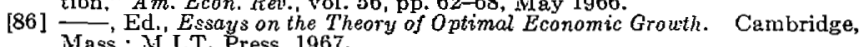

87] Mass.: M.I.T. Press, 1967.

which there is exogenous technical change," in Essays on the Theory of which there is exogenous technical change," in Essays on the Theory of
Optimal Economic Growth, K. Shell, Ed. Cambridge, Mlass.: M.I.T. Optimal Econo
Press, 1967.

[88] K. Shell and J. Stiglitz, "The allocation of investment in a dynamic 89] K. Shell, "Quart. J. Ecan., vol. 81, November 1967.

K. Shell, "Applications of Pontryagin's maximum principle to economies," Lectures given at the International Summer School for MatheTechnology. Cambridge, Working paper 16, 1968 .

[90] E. Sheshiuski, "Optimal accumulation with learning by doing," in Essays on the Theory of Optimal Economic Growth, $\mathbf{K}$. Shell, Ed. Cambridge,

1] R. M. Solow, "Some recent developments in the theory of production," presented at the Nat'l Bureau of Economic
in Income and Vealth, October $15-16,1965$.

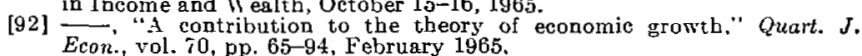

[93] T. M. Srinivasan, "Optimal savings in a two-sector model oi economic

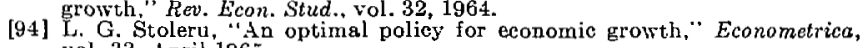

vol. 33 , April 1965 .

[95] R. Stone. A Computable Model of Economic Growth. Carobridge, Mass.:

[96] R. Strotz, "Myopia and inconsistency in dynamic utility maximization,"

[97] Tex. Econ. Stud,., Yol, 23, 1956.

[98] J. Tinbergen, "The optimal rate of savings," Econ. J., vol. 66, 1956.

[99] "Optimum savings and utility maximization," Econometrica, vol.

100] U.S. Dept. of Commerce, Nat'l Income Div., National Income: A Supplement to the Survey of Current Business. Wushington, D.C.: U. S. Goverment Printing Office, 1954

[101] U.S. Dept. of Commerce, Office of Business Economics, $L . S$. Income and

102] H. Cut. Wawa. "Preference and rational choice in the theory of consunption," in Mathematical Ifethods in the Social Sciences, $\mathrm{K}$. J. Arrow. S. Karlin, and P. Suppes, Eds. Stanford, Calif.: Stanford Liviversity Press. 1960.

[103] "Optimum techaical change in an aggregative nodel of economic [104] grow'th." Internat'l Econ. Rev., vol. 6, pp. 18-31, January 1965.

104 1 - "Optimal growth in a two-sector model of capital aceumulation,"

[105] C. C. Yon W eizs. vol. 31, 1964

an infinite time horizon." Rex ence of optimal programs of accumulation for

(106) H. I. II an. "Intertemporal optimization with ststematically shiting cost

(107) and resenue functions," Internat'l Econ. Rev., vol. i, i.

107) II. Yaari, "Uncertain lifetime, life insurance, and the theory of the conSimer," Rev. Econ. Stud., vol. 32, pp. 137-150, April 1965 .

$[108]$ M. Yanorsky, social Accounting Systems., Chicago: Aldine, 1965. 1968 .

[110] T. C. Koopmans, "Objectives, constraints and outeomes in optimal growth models," Econometrica, vol. 35 , January $196 \bar{\gamma}$.

[111] R. Radner, "Efficiency prices for infinite horizon prorrammes," Rew.

[111] R. Radner, "Efficiency prices for infinite $1121 \mathrm{~K}$. Vind, "Control systems with jumps in the state variables." Econo-
metrica, vol. 35 , April 1967

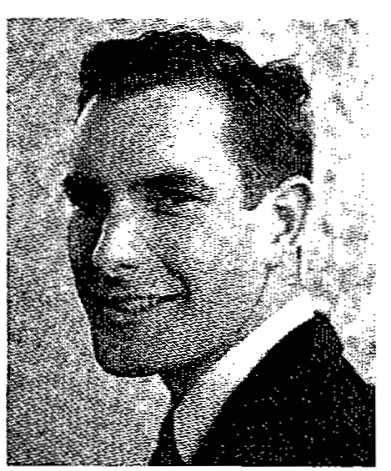

A. R. Dobell was born in Taucouver, B.C., Canada, on April 27, 1937. He received the B.A. degree in mathematics and economies and the M.A. degree in mathematics from the University of British Columbia, Vancouver, in 1959 and 1961 , respectively, and the cioctorate degree in economics from the Massachusetts Institute of Technology, Cambridge, in 1965.

He was Assistant Professur of Economics at Harvard Lniversity, Cambridge, Mass, from 1964 to 1968. At present, he is Associate Professor of Mathematics and Political Econtumy at the University of Toronto, Toronto, Ont., Canada, specializing in theories of economic growth and optimal policy. He has coauthored papers on random number generators and on economic grow th models.

Dr. Dobell is a member of the American Economic Association and the Econometric Society. 